\title{
Volatility Modelling of Chinese Stock Market Monthly Return and Investor Sentiment Using Multivariate GARCH Models
}

\author{
Hongjun Zeng \\ Business School \\ Guangxi University \\ Nanning, China \\ E-mail: hongjunzeng@protonmail.com
}

\begin{abstract}
This article examines the linkage and volatility spillover among Chinese Stock Market Monthly Return and Investor Sentiment, investigating the effect dynamic links of various investor sentiment indicators and Chinese stock market return volatility. Employing the DCC and BEKK GARCH, we find investor sentiment is to some extent linked to the yield fluctuations of the Chinese stock market, but the volatility spillover is relatively weak. In the test period (2005-2020), we observe that several indicators do not explain their linkage effects with CSI 300 index of return fluctuations and volatility spillovers well, with no indicators can reflect both of these effects. Most indicators are linkage with the CSI 300 index, especially consumer confidence index (CCI), new investor account openings last month (NIA) and the volume of transactions last month (TURN) have significant linkage effects with the CSI 300 index. We also find that only the CCI index has a one-way volatility spillover on the CSI 300 index, and the CSI 300 index has no volatility spillover on any indicator.
\end{abstract}

Keywords: Stock Market Monthly Return, Investor Sentiment, volatility spillovers, Linkage, BEKK/DCC-GARCH.

\section{Introduction}

A well-developed financial market can significantly drive a country's economy by appropriately reallocating resources. On the opposite side, a less effective financial market system brings negative impacts and losses to a nation. Therefore, the stock market has gradually been an essential part of a country's economic and financial development. Volatility which reflects the stability of a financial system is an essential measure of financial market risk, and excessive volatility can lead to higher market risk (Campbell, Huisman, and Koedijk (200I). During the 30 years of development of the Chinese stock market, the Chinese stock market has experienced several violent shocks, stock index surges and plunges, and yields have fluctuated dramatically. The emergence of this phenomenon has a variety of factors such as policy, system, world economic situation, but one of the forces that can never be ignored is the irrationality of investors. The structural characteristics of Chinese investors are distinct, and individual investors occupy a very high proportion, and individual investors due to the high investment enthusiasm and lack of investment experience, the strong desire for profit and poor risk awareness, and in other hands, it is prone to the stock market trend of false expectations, there is an estimated deviation in asset prices, to make unreasonable judgments and choices. Of particular note is the "herd effect" in the Chinese stock market (Yao, Ma, \& He, 20I4).

In the deployment of China's national economic work in 2005, it replaced the prudent fiscal policy with the active fiscal policy, proposed a prudent fiscal policy and monetary policy, and in this year, the Chinese government carried out a reform of the exchange rate system, leaving the fixed exchange rate system in favour of a managed floating exchange rate system. These changes have had a particular impact on China's industrial structure, import and export industries and consumer demand, and the exchange rate has a growing impact on China's economy, and exchange rate reform will also promote the development of China's stock market. Therefore, this paper from 2005 as a starting point, in the stock market better development of the situation to research the impact of investor sentiment on the stock market yield volatility.

Through the DCC-GARCH model, we will be able to obtain the dynamic correlation coefficient among investor sentiment indicators and stock market yield volatility, so that investors can better understand the correlation among the two at each point in time, provide a more accurate basis for future forecast analysis, and help financial market policymakers to make more accurate judgments, reduce the phenomenon of large fluctuations in the stock market caused by the introduction of new policies. Third, on the research method of volatility spillover relationship, most scholars use the mean equation as the single variable GARCH, EGARCH or the modified EGARCH model in the form of ARMA, and most studies use virtual variables to compare and estimate the volatility changes of the spot market before and after the launch of stock index futures. However, similar methods fail to take full advantage of data implied information and have more parameters to be estimated. The advantage of choosing the 
BEKK-GARCH model is that it is simple to operate and does not require more constraints, and is conducive to promising the positive characterization of the variance matrix and the covariance matrix. The multivariate-GARCH model in the form of BEKK can find the volatility spillover effect by using the fluctuation information of each sequence to find the volatility spillover effect more fully using the variance of the time sequence and the covariance data. Therefore, the research content of this paper has some theoretical and practical significance for the research of the world's emerging markets.

\section{Literature Review}

Investor sentiment (IS) is a positive or negative sentiment on the investment market as a result of an investor's expected judgment of the trend of the ups and downs of the assets to be invested. Zweig (I973) considered that investor sentiment is a deviation among the subjective psychological pricing of risk assets and the actual value of assets. The introduction of this definition, to some extent, led to the later researchers on the definition of investor sentiment. Kyle (I985) first coined the term "noise trading". Black (1986) puts forward the true significance of the study of "noise traders", which refers to false or misjudged information that appears in the market. De Long, Shleifer, Summers, and Waldmann (I990) proves that investor sentiment is an intrinsic factor affecting the equilibrium price of stocks through the Noise Trader (DSSW) model. The Behavioral Asset Pricing Model (BAPM) and behavioural portfolio theory (BPT) put forward by Shefrin and Statman (I994) argued that investor sentiment reflects market participants' expectations for the future or willingness to invest, and is an important factor in reflecting investor psychology. Barberis, Shleifer, and Vishny (1998) by constructing an investor sentiment model, it is verified that investors can overreact or slow because of investor sentiment. Brown (1999) used the closed-end fund discount rate to estimate investor sentiment and found that it had a positive effect on stock market volatility. Fisher and Statman (2000) found that investor sentiment, both for professional and individual investors on Wall Street, is negatively correlated with future stock yields. Brown and Cliff (2004) found that investor sentiment is the overall optimism or overall negative sentiment in the investment process. Baker and Stein (2004) argue that investor sentiment represents investors' speculative tendencies and miscalculations about risky assets. Hirshleifer and Shumway (2003) found that in the major stock exchange markets in 26 countries, the upbeat mood generated by the early morning sun was significantly correlated with daily market index earnings. Polk and Sapienza (2009) use the incorrect pricing of stocks to define investor sentiment. Sayim and Rahman (2015) Using data from the Turkish capital market to build investor sentiment indicators, the results show that investor sentiment can significantly influence asset prices and price fluctuations.

In the recent literature on investor sentiment, stock trading data is applied more as a proxy indicator of investor sentiment. Baker and Wrugler (2006) emphasized the importance of selecting a quantitative approach to investor sentiment. They examine that the problem that investor sentiment research wants to solve is not to prove the correlation among investor sentiment and the stock market, but to find ways to measure its relevance. Prior to that, Baker and Wurgler (2004) used the turnover rate as a measure of investor sentiment in its study of the impact of investor sentiment on the stock market, arguing that liquidity in the stock market reflected investor sentiment. Peng and Xiong (2006) found that limited attention can trigger class learning behaviours for investors. Veldkamp (2006) found that in the emerging markets, group behaviour among investors has something to do with media coverage. The study by Kaustia and Knüpfer (2008) found that IPO data has an important impact on investor sentiment. Schmeling (2009) uses a single consumer confidence index to represent sentiment. He selects CCIs from I8 countries with different economic conditions to represent investor sentiment in different countries. The results show that the size of the herd effect in the stock market is related to the influence of investor sentiment on the stock price. Chen, Chong, and Duan (20I0) considers volume to be the ideal proxy variable for estimating investor sentiment. Ben-Rephael, Kandel, and Wohl (2012) used the net exchange of stocks and funds to show investor sentiment in the stock market and fund market, respectively and studied the relationship among investor sentiment and excess returns in the stock market and fund market, respectively. Meanwhile, Lee, Shleifer, and Thaler (I99I) proposed that investor sentiment could be replaced by closed-end fund discount rates. Andrikogiannopoulou and Papakonstantinou (2018) find that the effect of disposal was driven primarily by unrealized capital gains and that the higher the power when demand price elasticity was low, validating the disposition of investors holding loss-making stocks. Trejos, van Deemen, Rodríguez, and Gomez (2019) an exploratory analysis of demographic factors and investor performance characteristics shows that investors with short investment horizons, more experience and investment in large-cap stocks are more susceptible to overconfidence. At last, Da, Engelberg, and Gao (2015) points out that the questionnaire method cannot be used in high-frequency data, and that results will become increasingly unreliable if the response rate in the survey is high or the motivation for telling the truth is low.

Some recent stock market volatility and investor sentiment related researches also used GARCH model. Lee (20I4) applied the CBP-GARCH to research the Nikkei 225 and VXJ indexes from I998 to 20I2, and report empirically evidence that the returns of the Japanese futures market have a significant impact on investor sentiment. Owji and Kontonikas (2018) find that using three most valuded stock indices in Europe, such as FTSE 100, DAX\&CAC, employing four different methodologies, including $\mathrm{ARCH}(\mathrm{I}), \mathrm{GARCH}(\mathrm{I}, \mathrm{I})$, GJR-GARCH(I, I) and EGARCH(I, I), then choosing 5 macro-economic variables (Turnover, Consumer Confidence, Inflation, Industrial Production Growth, and Money Supply), the authors find that the no clear evidence showing which is the best model to capture volaitility for FTSE IOO index, while the best model for DAX is EGARCH $(\mathrm{I}, \mathrm{I})$, and the best model for CAC index is GARCH (I, I). 


\section{Data and Methodology 3.I Identify Indicator}

The CSI 300 index is composed of 300 stocks with large market capitalization and good liquidity in the Shanghai and Shenzhen stock markets. It comprehensively reflects the overall performance of the price of listed stocks on the Chinese A-share market. Therefore, we use the monthly logarithmic return index of the CSI 300 index as the core variables of the study.

For the identity of the investor sentiment index, we draw on the BW index of Baker and Wurgler (2006) and the general investor sentiment structured by Baker, Wurgler, and Yuan (20I2). We directly select the Investor Confidence Index (CICSI), the number of new investor accounts (NIA) and the volume of transactions last month (TURN), the Consumer Confidence Index (CCI) in the CSMAR database as the research variables.

Consumer Confidence Index (CCI): CCI is an indicator of the strength of consumer confidence, a comprehensive reflection and quantification of consumer seethes and economic outlook, income levels, income subjective perception of the state of consumer psychology, and a leading indicator of predicting economic and consumption trends. This indicator is conducted by China's National Bureau of Statistics' China Economic Climate Monitoring Center, which conducts questionnaires, statistics on urban consumers and publishes them.

New investor account openings last month (NIA): The number of new investor account openings (NIA) last month refers to the number of new active accounts added to the stock market each month. This data can reflect the change in the time and quantity of investors entering the market, but also, to a large extent, reflects the enthusiasm of investors to participate in the stock market. When investors are optimistic, their enthusiasm for participating in the market is high, prompting new investors to enter the securities market and open a sharp increase in the number of accounts. When investors are pessimistic, the market is on the sidelines, and the market downturn will curb the speculation of new investors and the impulse to enter the market. Meanwhile, the number of new investor account openings accounts (NIA) was chosen last month because the indicator is a good indicator of investor sentiment in China's developing stock market.

The volume of transactions last month (TURN): The volume of transactions last month (TURN) refers to the number of transactions in the previous month. The volume of transactions last month (TURN) is an essential indicator of market movements, reflecting the activity of the market and the size of funds. According to the theory of supply and demand, turnover is the dominant stock price. When investors are in high spirits, the willingness to enter the stock market is strong, oversupply, driving up share prices.

The China Investor Confidence Index (CICSI) is a new tool for collecting hundreds of millions of financial texts of big data that the network can reflect investor sentiment, using deep learning methods to measure text messages to reflect the sentiment of individual investors in China.

\subsection{Research Methods}

In the empirical analysis of the impact of investor sentiment on stock market monthly yield, this article first carries on the ADF test of the time series data of the variables, uses ARCH for a statistical test, and analyzes the economic significance of the relevant coefficients.

In the empirical analysis of the relationship among investor sentiment indicators and the monthly positive yield of CSI 300 index, the DCC-GARCH model put forward by Engle (2002) is selected. The main advantage of the DCC-GARCH is that the model's evaluation parameters are relatively small compared to other models, so it has a significant advantage in the calculation. It can obtain dynamic correlation coefficients between different variables, which can better depict the correlation between multiple variables.

In the analysis of the spillover effect of the monthly reciprocal yield fluctuation of the investor sentiment index and the CSI 300 index, the BEKK-GARCH model has been applied. Engle and Kroner (1995) constructed the BEKK-GARCH to the rmaritan the coefficient matrix of the co-sorting to maintain the right positiveness of co-guardian matrix.

Here in this article, the above chapter of the investor sentiment composite index to do differential treatment, reduce randomness and thus ensure stability, select the CSI 300 index monthly reciprocal yield. A total of I8I data were selected to study the linkage and volatility spillover effect of the monthly yield of the CSI 300 Index, and I8I months from January 2005 to February 2020 were selected (Monthly data are derived from the REESE database).Select the monthly logarithmic return rate of the CSI 300 index, and the specific formula is as follows:

$$
y_{t}=\operatorname{in}\left(x_{t}\right)-\operatorname{in}\left(x_{t-1}\right), t=1,2, \ldots, n \text {. }
$$

\subsection{GARCH Model}

The basic ARCH model only applies to short-term self-correlation processes for heater variance functions, but not all heater related functions are short-term self-correlation processes, and some are in practice long-term self-correlation. In this case, if the model is still used, it will significantly add the difficulty of parameter estimation, which in turn will affect the fit accuracy of the ARCH model. Bollerslev (1986) expanded ARCH and proposed GARCH model to exchange of the lag of many random error 
terms with the lag of one or more variances. The GARCH model es one or more random in the lag to the memory of the arch model, who is ed by the severity of the volatility of the time of the financial series.

$$
\begin{aligned}
& \varepsilon_{t}=\sigma_{t} \eta_{t} \sim \text { i.i.d }(0,1) \\
& \sigma_{t}^{2}=\omega+\sum_{i=1}^{q} \alpha_{i} \varepsilon_{t-i}^{2}+\sum_{j=1}^{p} \beta_{j} \sigma_{t-j}^{2}
\end{aligned}
$$

\subsubsection{BEKK-GARCH Model}

Compared with other multivariate GARCH, the research object of the BEKK-GARCH model is the volatility spillover effect among financial time series, which can simultaneously reflect the significance and direction of the volatility spillover effect. Besides, the BEKK-GARCH model guarantees the positive definiteness of the covariance matrix under weak constraints, fewer estimated parameters, and low computational complexity. The BEKK can be express below as:

$$
H_{t}=C^{\prime} C+\sum_{k=1}^{K} C_{1 k} x_{t} x_{t}^{\prime} C_{1 k}+\sum_{k=1}^{K} \sum_{i=1}^{q} A_{i k}^{\prime} \varepsilon_{t-i} \varepsilon_{t-i}^{\prime} A_{i k}+\sum_{k=1}^{K} \sum_{i=1}^{p} G_{i k}^{\prime} H_{t-i} G_{i k}
$$

Where, $x_{t}$ is an exogenous variable.

The bivariate BEKK GARCH $(I, I)$ without exogenous variables which is express as:

$$
H_{t}=C^{\prime} C+A^{\prime} \varepsilon_{t-1} \varepsilon_{t-1}^{\prime} A+G^{\prime} H_{t-1} G
$$

\subsubsection{DCC-GARCH Model}

Due to VECH can't describe the volatility characteristics completely, and CCC-GARCH model ignores the time-varying characteristics of correlation coefficient between sequences. Engle (2002) proposed the DCC-GARCH model. The DCCGARCH model can well describe the dynamic correlation between multiple time series. Assuming $\gamma_{t}=\left(\gamma_{1, t}, \gamma_{2, t}, \ldots, \gamma_{k, t}\right)$ is $k$ financial time series, the DCC-GARCH model should be expressed as follows:

$$
e_{t} \sim N\left(0, H_{t}\right)
$$$$
H_{t}=D_{t} R D_{t}
$$

$D_{t}=\operatorname{diag}\left(\sqrt{h_{11, t}} \cdots \sqrt{h_{n n, t}}\right)$

$$
R=\left(Q_{t}^{*}\right) Q_{t}\left(Q_{t}^{*}\right)^{-1}
$$

$$
Q^{*}=\operatorname{diag}\left(\sqrt{q_{11, t}} \cdots \sqrt{q_{n n, t}}\right)
$$

Where ${ }{ }_{t}$ obeys the following dynamic equation:

$$
Q_{t}=(1-\alpha-\beta) \bar{Q}+\alpha\left(\varepsilon_{i, t-1} \varepsilon_{i, t-1}^{\prime}\right)+\beta Q_{t-1}
$$

Where, $R_{t}$ is the time-varying conditional correlation coefficient matrix, $h_{11, t}$ is the conditional variance of each sequence.The constraint of the DCC model is to promise the positive definiteness of $H_{t}$, therefore the conditions to be satisfied for this model are $\alpha \geq \beta, \beta \geq 0, \alpha+\beta<1$ and $Q_{0}$ is positive definite.

\section{Primary Analyse}

First and foremost, make the intuitive time series figures of The volume of transactions last month(TURN), Consumer Confidence Index(CCI), New investor account openings last month (NIA), The China Investor Confidence Index (CICSI) and the CSI 300 Index monthly logarithmic returns, respectively.( Empirical analysis uses $\mathrm{R}$ version 3.6.3) 

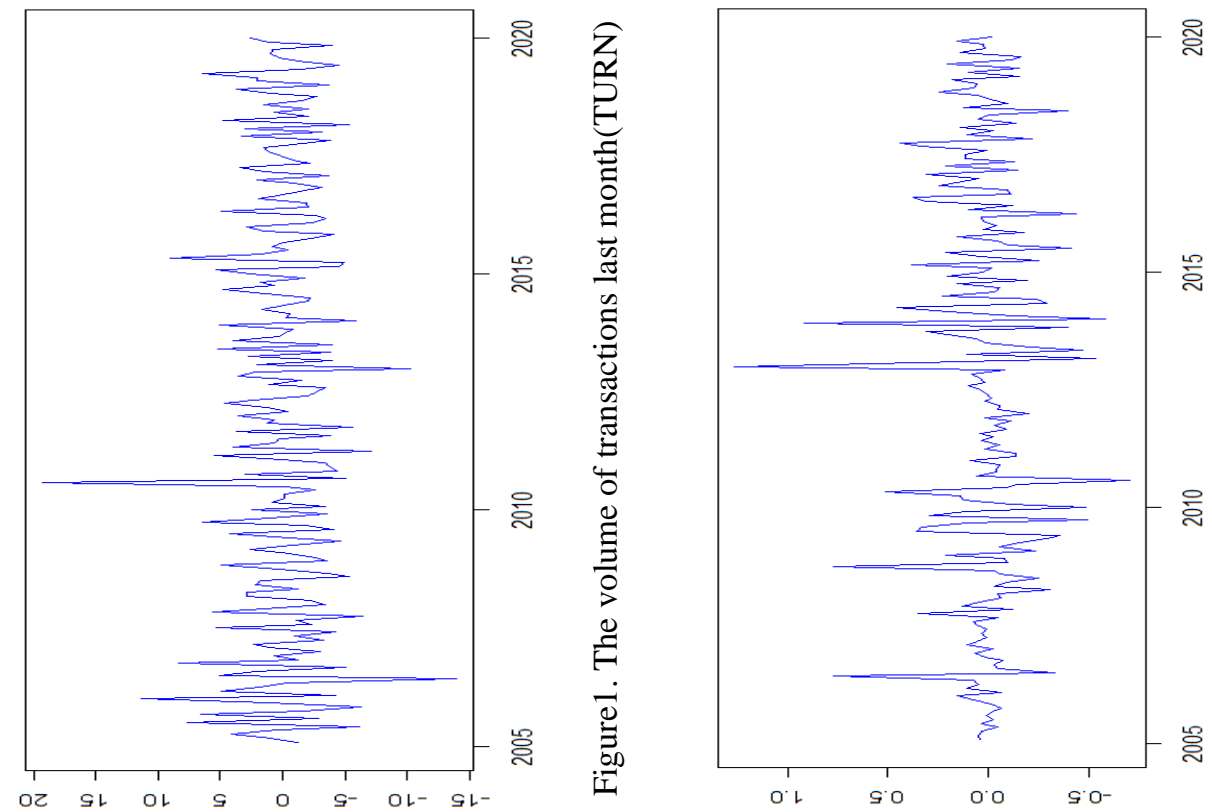

ลิ

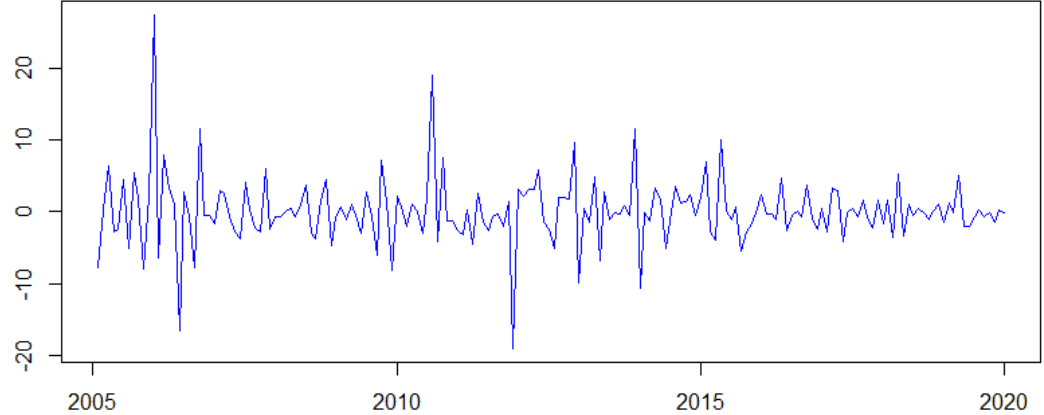

Figure 3. New investor account openings last month (NIA)

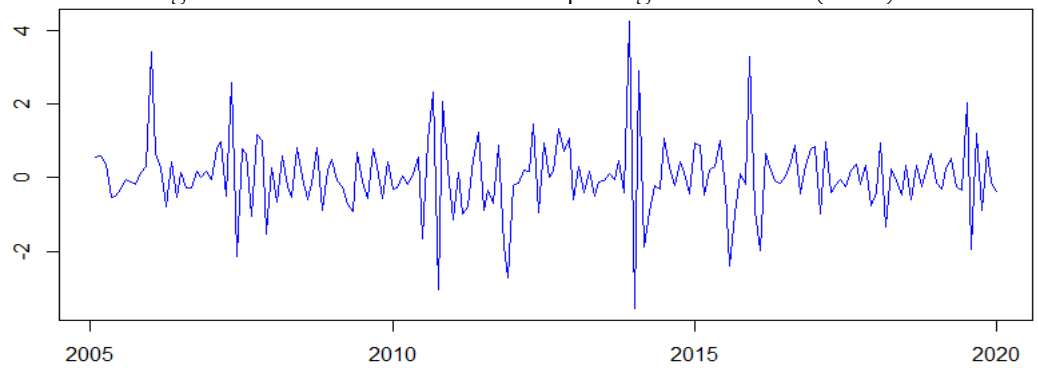

Figure 4. The China Investor Confidence Index (CICSI)

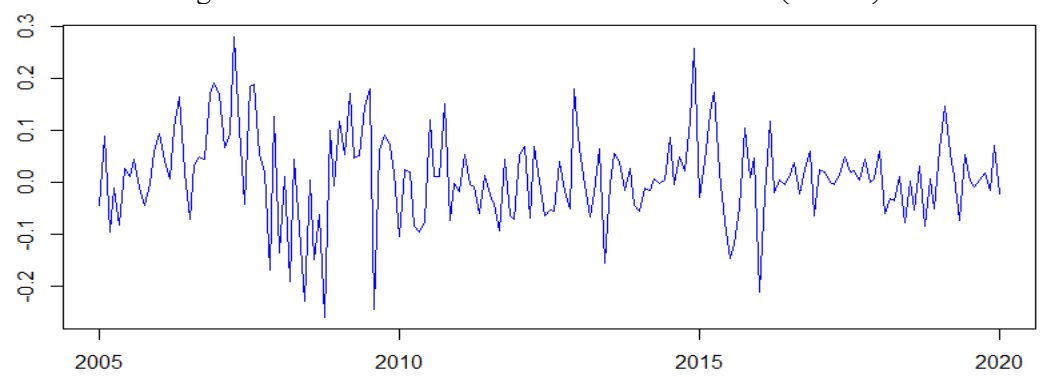

Figure 5. CSI 300 Index monthly logarithmic returns 
We can see the figure above, these five-time series have a certain degree of volatility aggregation. The prerequisite for applying GARCH modelling is that the time series must be smooth, so this paper first makes a smooth test of the above indicators before modelling, and this paper uses $\mathrm{ADF}$ and $\mathrm{ARCH}$ tests to determine the stationary.

Table. I. The results of ADF and ARCH

\begin{tabular}{lllllc}
\hline & TURN & NIA & CCI & CICSI & CSI 300 \\
\hline ADF & $-\mathrm{I} 3.1866$ & $-\mathrm{I} 2.2 \mathrm{I} 74$ & $-\mathrm{I} 0.870 \mathrm{I}$ & $-\mathrm{II} .4787$ & -7.5075 \\
& $(0.000)$ & $(0.000)$ & $(0.000)$ & $(0.000)$ & $(0.000)$ \\
\hline $\mathrm{PP}$ & $-\mathrm{I} 99.3563$ & $-2 \mathrm{I0.272}$ & $-\mathrm{I} 90.9508$ & -234.4683 & $-\mathrm{I} 72.67 \mathrm{I}$ \\
& $(0.000)$ & $(0.00 \mathrm{I})$ & $(0.048)$ & $(0.000)$ & $(0.040)$ \\
\hline Result & Stationary & Stationary & Stationary & Stationary & Stationary \\
\hline ARCH & O.00I & 0.00I & 0.00I & 0.00I & $0.00 \mathrm{I}$ \\
\hline Conclusion & Existence & Existence & Existence & Existence & Existence \\
\hline
\end{tabular}

Furthermore, above table is the test result of the ADF and ARCH tests, and it is known that the five-time series are strictly stationary, which is consistent with the visual observation of the five-time series diagrams above.

\section{Empirical Analysis 5.I The result of DCC-GARCH model}

Table 2. The results of DCC-GARCH model

\begin{tabular}{lcccc}
\hline & Estimate & Std. Error & T value & $\operatorname{Pr}(>|t|)$ \\
\hline [turn].omega & 0.000000 & $0.00013 \mathrm{I}$ & 0.000775 & 0.999382 \\
[turn].alphaI & 0.000000 & 0.001109 & 0.000022 & 0.999982 \\
[turn].betaI & 0.997710 & 0.000277 & 3603.899730 & 0.000000 \\
[nia].omega & 0.000000 & 0.000006 & 0.000979 & 0.999219 \\
[nia].alphaI & 0.011592 & $0.00672 \mathrm{I}$ & $\mathrm{I} .724857$ & 0.084553 \\
[nia].betaI & 0.979742 & 0.006706 & $\mathrm{I} 46.104878$ & 0.000000 \\
[cci].omega & 0.049600 & 0.026839 & 1.848042 & 0.064596 \\
[cci].alphaI & 0.098344 & 0.072510 & $1.35628 \mathrm{I}$ & 0.175010 \\
[cci].betaI & 0.000000 & 0.395190 & 0.000000 & 1.000000 \\
[cicsi].omega & 0.000457 & 0.028897 & 0.015799 & 0.987395 \\
[cicsi].alphaI & 0.000000 & 0.031969 & 0.000000 & 1.000000 \\
[cicsi].betaI & 0.999000 & 0.002100 & 475.753122 & 0.000000 \\
[csi].omega & 0.000412 & 0.000236 & 1.745438 & 0.080909 \\
[csi].alphaI & 0.231299 & 0.115984 & 1.994236 & 0.046126 \\
[csi].betaI & 0.731331 & 0.091176 & 8.021085 & 0.000000 \\
[Joint]dccalpha 0.000000 & 0.000025 & 0.002066 & $0.99835 \mathrm{I}$ \\
[Joint]dccbeta & $0.88671 \mathrm{I}$ & $0.26399 \mathrm{I}$ & 3.358868 & 0.000783 \\
[Joint]mshape & 6.885936 & $\mathrm{I} .106189$ & 6.224916 & 0.000000 \\
\hline
\end{tabular}

Because of the alpha+beta $<\mathrm{I}$ of each indicator, it can be concluded that the selected investor sentiment indicator is relevant to the CSI 300 Index earnings volatility. Besides, it is shown that the standardised residual series of lag first-order trading volume (TURN) and investor confidence index (CICSI) does not have the dynamic correlation coefficient effect of the monthly/monthly yield of the CSI 300 index, but at the same time reflects the dynamic correlation coefficient of monthly. For the Consumer Confidence Index (CCI) and the number of new accounts (NIA) last month, alpha's value is relatively small, and the value of beta is close to I. Therefore, the results also indicate that the dynamic correlation coefficient of the monthly marital yield of the investor sentiment composite index and CSI 300 index is affected by its volatility in the early period, and points the relatively stable volatility persistence. Overall, the dec alpha value is 0 , and there is no dynamic correlation coefficient effect with the CSI 300 index monthly convection yield, and the dccbeta value is very close to I, indicating that the volatility is very continuous. 


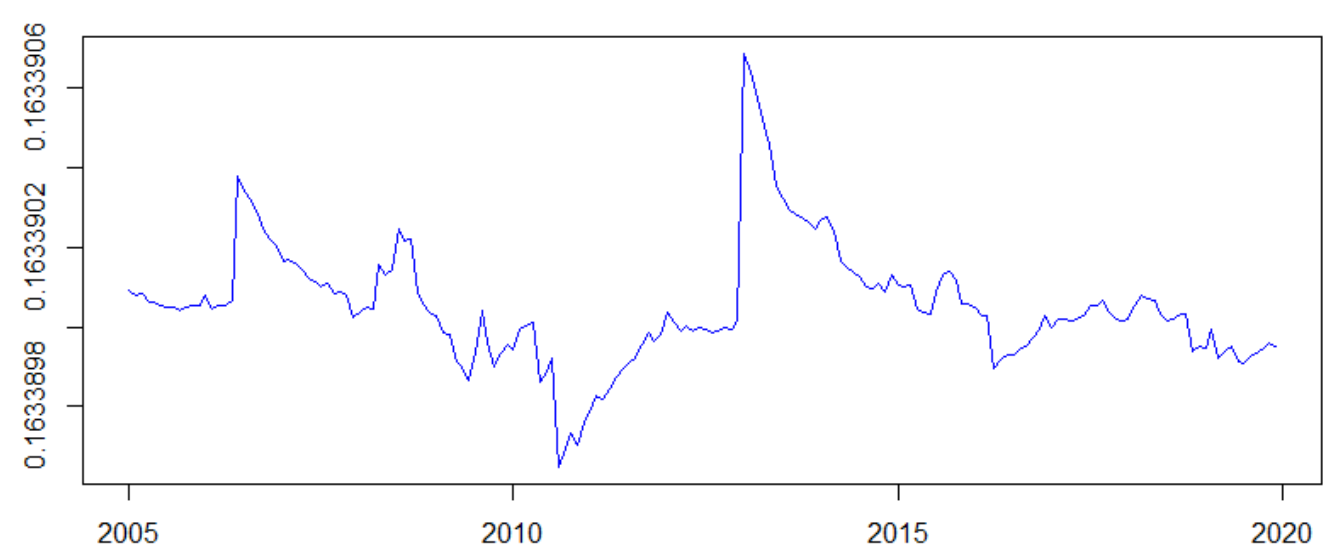

Figure 6. DCC Conditional Correlation (CCI-CSI 300)

We can see that the dynamic correlation coefficient is concentrated in around 0.I633 fluctuations, with stable volatility persistence, the entire range of fluctuations is stable in a small range, the overall volatility is not very large. Dynamic correlation coefficients are positive and show that there is a relatively stable positive correlation among the Consumer Confidence Index (CCI) and the CSI 300 yield, i.e. when consumer confidence is relatively high, consumers' willingness to invest in more reliable, the stock price will rise, the CSI 300 index yield fluctuates more, and vice versa. The correlation coefficient of 0.I633 indicates that the correlation is not very high, but considering that the trend of the stock market does not follow the correlation between subjective sentiment and stock market yield volatility will change at all times, people's mood will be affected by many factors. Therefore, in the study of the dynamic correlation coefficient among the two, the correlation coefficient is not very high, is a normal phenomenon.

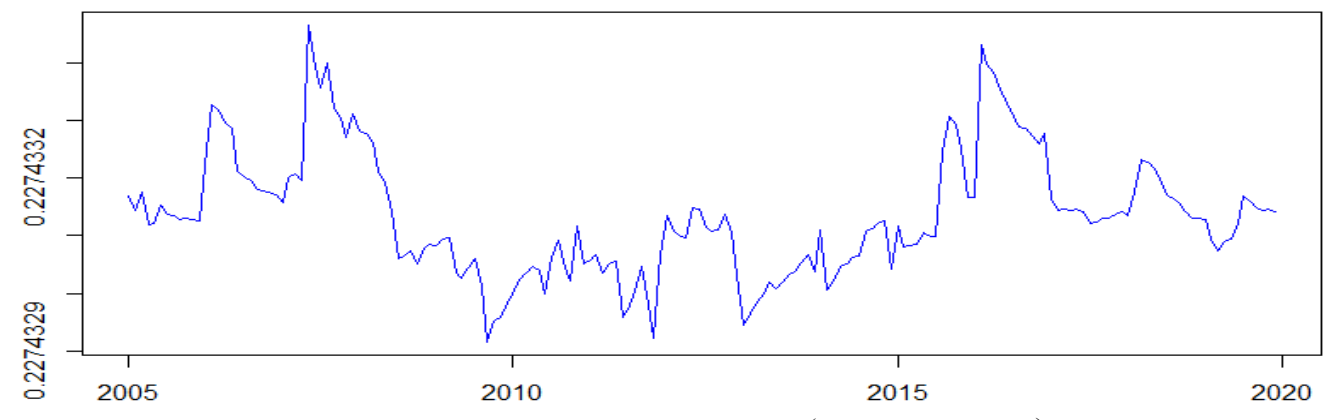

Figure 7. DCC Conditional Correlation (CICSI -CSI 300)

We can see that there is no dynamic correlation coefficient effect of the fluctuating rate of return on the CSI 300 index return monthly, the entire range of fluctuations is extensive, and the overall volatility is tremendous. The positive correlation coefficient indicates that there is a positive correlation among the investor confidence index (CICSI) and the CSI 300 yield. This may be related to an intense overreaction in the Chinese stock market, where Chinese investors have a clear cognitive bias and speculative tendencies ( $\mathrm{Ni}$, Wang, \& Xue, 2015).

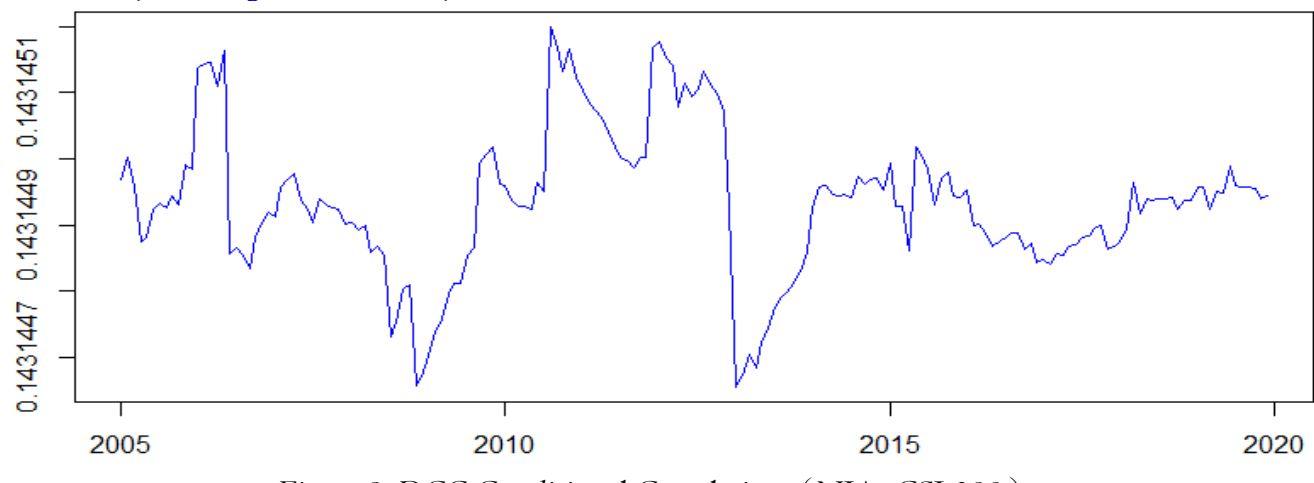

Figure 8. DCC Conditional Correlation (NIA -CSI 300) 
We can see that the dynamic correlation coefficient is concentrated in around 0.I43I fluctuations, in stable volatility continuity, the entire volatility range is stable in a minimal range. The total volatility is not very large. The dynamic correlation coefficient is positive and then indicates that New investor account openings last month (NIA) and CSI 300 yield among a more stable positive correlation. When the NIA increase, consumers' investment intentions also will rise, the stock price will be raised, The CSI 300 index will be yield volatility will be significant, and vice versa. Correlation coefficient 0.I43I indicates that the correlation level is not very high. Similarly, the dynamic correlation coefficient is not very different from the Consumer Confidence Index (CCI), so there is a necessary consensus conclusion.

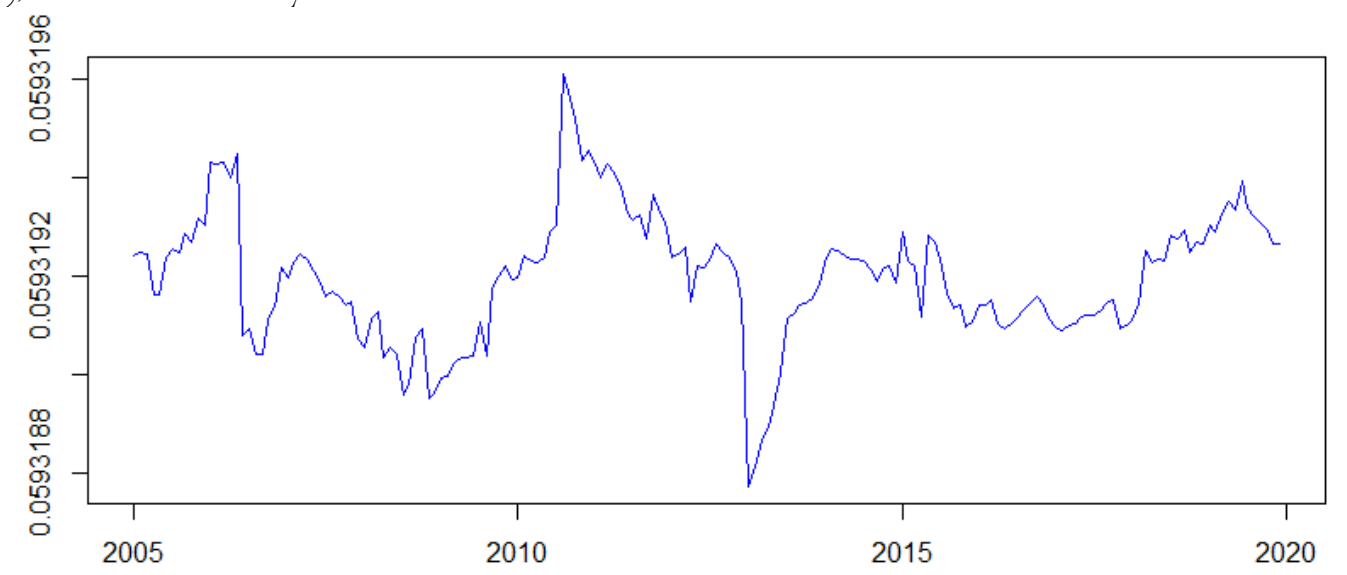

Figure 9. DCC Conditional Correlation（TURN -CSI 300）

We can see that the dynamic correlation coefficient is concentrated in around 0.0593 fluctuations, with very stable volatility continuity; the entire volatility range is stable in a small range, the overall volatility is minimal. The dynamic correlation coefficient is positive and then shows that the volume of transactions last month (TURN) and CSI 300 yield between a very stable positive correlation between, that is the volume of transactions last month (TURN) add more consumers' investment willingness, the stock price will be raised, CSI will be raised with it. The CSI 300 index yield volatility greatly, and vice versa. Correlation coefficient 0.0593 indicates that the correlation is not high. Similarly, the dynamic correlation coefficient is not very different from the Consumer Confidence Index (CCI), so there is a necessary consensus conclusion.

\subsection{The results of BEKK-GARCH model}

Table 3. The results of BEKK-GARCH model

\begin{tabular}{|c|c|c|c|c|}
\hline Variable & Coeff & Std Error & T-Stat & Signif \\
\hline 6. $C(I, I)$ & $\mathrm{I} .58077947$ & 0.32001475 & $4.9397 \mathrm{I}$ & 0.00000078 \\
\hline 7. $C(2, I)$ & 0.91994463 & 0.38183787 & 2.40925 & 0.01598514 \\
\hline 8. $C(2,2)$ & -0.00344812 & 0.46386908 & -0.00743 & 0.99406907 \\
\hline 9. $\mathrm{C}(3, \mathrm{I})$ & 0.01945736 & 0.02331095 & 0.83469 & $0.4038937 \mathrm{I}$ \\
\hline I0. $C(3,2)$ & -0.00003905 & 0.03093267 & -0.00126 & 60.99899264 \\
\hline II. $C(3,3)$ & -0.0001 I I I8 & 0.03055768 & -0.00364 & $\begin{array}{ll}4 & 0.99709694\end{array}$ \\
\hline I2. $\mathrm{C}(4, \mathrm{I})$ & 0.16957934 & 0.I I098860 & I.52790 & 0.12653768 \\
\hline I3. $\mathrm{C}(4,2)$ & -0.00137534 & 0.14337207 & -0.00959 & 0.99234617 \\
\hline I4. $C(4,3)$ & $0.0008744 \mathrm{I}$ & 0.13927518 & 0.00628 & 0.99499067 \\
\hline I5. $\mathrm{C}(4,4)$ & 0.00023855 & 0.10460990 & 0.00228 & 0.99818052 \\
\hline I6. $\mathrm{C}(5, \mathrm{I})$ & -0.00397893 & 0.00713824 & $-0.5574 \mathrm{I}$ & 0.57724694 \\
\hline I7. $\mathrm{C}(5,2)$ & $-0.000 \mathrm{I} 4474$ & $0.0155949 \mathrm{I}$ & -0.00928 & 0.99259500 \\
\hline I8. $\mathrm{C}(5,3)$ & -0.00006236 & 0.01059646 & -0.00588 & 0.99530480 \\
\hline I9. $\mathrm{C}(5,4)$ & -0.00012589 & 0.00779195 & -0.01616 & 0.98711009 \\
\hline 20. $\mathrm{C}(5,5)$ & 0.00003525 & 0.00899129 & 0.00392 & 0.99687230 \\
\hline 2I. $\mathrm{A}(\mathrm{I}, \mathrm{I})$ & $-0.295577 \mathrm{I} 4$ & 0.I I93204I & -2.47717 & 0.01324282 \\
\hline 22. $\mathrm{A}(\mathrm{I}, 2)$ & 0.01502438 & 0.I2I47254 & 0.12369 & 0.90156436 \\
\hline 23. $\mathrm{A}(\mathrm{I}, 3)$ & 0.00942509 & 0.00576770 & I.634I I & 0.10223494 \\
\hline 24. $\mathrm{A}(\mathrm{I}, 4)$ & -0.06519940 & 0.03244208 & -2.00972 & 0.04446116 \\
\hline
\end{tabular}




\begin{tabular}{|c|c|c|c|}
\hline 25. $\mathrm{A}(\mathrm{I}, 5)$ & -0.00520301 & 0.00225838 & -2.303860 .02123034 \\
\hline 26. $\mathrm{A}(2, \mathrm{I})$ & 0.22086374 & 0.09393095 & $2.35 \mathrm{I} 340.01870586$ \\
\hline 27. $\mathrm{A}(2,2)$ & $-0.0168372 \mathrm{I}$ & $0.0807610 \mathrm{I}$ & $-0.20848 \quad 0.83485268$ \\
\hline 28. $\mathrm{A}(2,3)$ & $-0.0056189 \mathrm{I}$ & 0.00494710 & -I.I3580 $0.2560405 \mathrm{I}$ \\
\hline 29. $\mathrm{A}(2,4)$ & 0.03531876 & 0.02348705 & I.50375 0.13264460 \\
\hline 30. $\mathrm{A}(2,5)$ & 0.00336215 & 0.00177852 & I.8904I 0.05870278 \\
\hline 3I. $\mathrm{A}(3, \mathrm{I})$ & 1.50989190 & 1.05958318 & I.42499 0.15416106 \\
\hline 32. $\mathrm{A}(3,2)$ & I.87786I9I & 0.85522104 & 2.195760 .02810898 \\
\hline 33. $\mathrm{A}(3,3)$ & 0.25715935 & 0.06872782 & $3.7417 \mathrm{I} \quad 0.00018277$ \\
\hline 34. $\mathrm{A}(3,4)$ & 0.19473227 & 0.24150293 & 0.806340 .42004969 \\
\hline 35. $\mathrm{A}(3,5)$ & -0.05124376 & 0.01974982 & $\begin{array}{lll}-2.59464 & 0.00946889\end{array}$ \\
\hline 36. $\mathrm{A}(4, \mathrm{I})$ & -0.16042345 & 0.28063105 & -0.57 I 650.56755740 \\
\hline 37. $\mathrm{A}(4,2)$ & $0.651 \mathrm{I} 8828$ & $0.2693964 \mathrm{I}$ & $2.4 \mathrm{I} 72 \mathrm{I} \quad 0.01563990$ \\
\hline 38. $\mathrm{A}(4,3)$ & $0.0073835 \mathrm{I}$ & 0.01410334 & 0.523530 .60060607 \\
\hline 39. $\mathrm{A}(4,4)$ & 0.21948855 & 0.07156609 & 3.066930 .00216266 \\
\hline 40. $\mathrm{A}(4,5)$ & 0.00373906 & 0.00672321 & $0.556 \mathrm{I} 40.578 \mathrm{II} 346$ \\
\hline 4I. $\mathrm{A}(5, \mathrm{I})$ & -18.81310263 & $3.800929 \mathrm{II}$ & $\begin{array}{lll}-4.9496 I & 0.00000074\end{array}$ \\
\hline 42. $\mathrm{A}(5,2)$ & -16.21219821 & 3.06912326 & $\begin{array}{lll}-5.28235 & 0.00000013\end{array}$ \\
\hline 43. $\mathrm{A}(5,3)$ & 0.27736917 & 0.19883426 & I.39498 0.16302285 \\
\hline 44. $\mathrm{A}(5,4)$ & $-\mathrm{I} .96799 \mathrm{I} 4 \mathrm{I}$ & 0.69288548 & $\begin{array}{lll}-2.84028 & 0.00450734\end{array}$ \\
\hline 45. $\mathrm{A}(5,5)$ & 0.38860793 & 0.11243665 & 3.456240 .00054777 \\
\hline 46. $\mathrm{B}(\mathrm{I}, \mathrm{I})$ & $0.8357356 \mathrm{I}$ & 0.17963098 & $4.6525 \mathrm{I} \quad 0.00000328$ \\
\hline 47. $\mathrm{B}(\mathrm{I}, 2)$ & 0.10448446 & 0.26379450 & $0.39608 \quad 0.69204396$ \\
\hline $48 \mathrm{~B}(\mathrm{I}, 3)$ & 0.01347245 & 0.01231498 & $\begin{array}{ll}1.09399 & 0.27395972\end{array}$ \\
\hline Variable & Coeff & Std Error & T-Stat \\
\hline 49. B(I,4) & -0.10058278 & 0.03849434 & $-2.612920 .008977 \mathrm{I} 3$ \\
\hline 50. $\mathrm{B}(\mathrm{I}, 5)$ & 0.00228750 & 0.00296875 & 0.770530 .44098680 \\
\hline 5I. B (2,I) & -0.19838333 & 0.12967391 & $-\mathrm{I} .529860 .1260506 \mathrm{I}$ \\
\hline 52. $\mathrm{B}(2,2)$ & 0.39211758 & 0.18802935 & $2.0854 \mathrm{I} \quad 0.03703244$ \\
\hline 53. $\mathrm{B}(2,3)$ & -0.05194982 & 0.00811020 & $\begin{array}{lll}-6.40549 & 0.00000000\end{array}$ \\
\hline 54. B $(2,4)$ & 0.13932893 & 0.02874143 & $\begin{array}{lll}4.84767 & 0.00000125\end{array}$ \\
\hline 55. $\mathrm{B}(2,5)$ & -0.00321549 & 0.00252437 & - I.27378 0.20274099 \\
\hline 56. $\mathrm{B}(3, \mathrm{I})$ & 3.67842160 & $\mathrm{I} .75107874$ & 2.100660 .03567080 \\
\hline 57. $\mathrm{B}(3,2)$ & 4.82493874 & I.827I4020 & $2.6407 \mathrm{I} \quad 0.00827337$ \\
\hline 58. $\mathrm{B}(3,3)$ & 0.48770485 & 0.08278423 & 5.891280 .00000000 \\
\hline 59. $\mathrm{B}(3,4)$ & 3.47313948 & $0.372544 \mathrm{I} 5$ & 9.322760 .00000000 \\
\hline 60. $\mathrm{B}(3,5)$ & 0.14697550 & 0.04072333 & 3.609120 .00030723 \\
\hline 6I. B $(4, I)$ & -1.90537237 & 0.52578589 & -3.623860 .00029024 \\
\hline 62. $\mathrm{B}(4,2)$ & -3.85134515 & 0.29907579 & -12.877490 .00000000 \\
\hline 63. $\mathrm{B}(4,3)$ & $-0.01330 I 14$ & 0.02503326 & -0.531340 .59518400 \\
\hline 64. $\mathrm{B}(4,4)$ & $-0.0445789 \mathrm{I}$ & 0.08656475 & $-0.5 \mathrm{I} 498 \quad 0.60656863$ \\
\hline 65. $\mathrm{B}(4,5)$ & -0.034 I I 638 & 0.01392885 & -2.449330 .01431213 \\
\hline 66. $\mathrm{B}(5, \mathrm{I})$ & 2.I I594779 & $3.5280226 \mathrm{I}$ & 0.599750 .54866979 \\
\hline 67. $\mathrm{B}(5,2)$ & -0.95489179 & 5.47963708 & -0.174260 .86165967 \\
\hline 68. $\mathrm{B}(5,3)$ & -0.49190568 & 0.20302258 & $-2.42291 \quad 0.01539669$ \\
\hline 69. $\mathrm{B}(5,4)$ & -I.33460203 & 0.94475399 & -I.4I265 0.15776012 \\
\hline 70. $\mathrm{B}(5,5)$ & $0.8 \mathrm{II} 65087$ & 0.05199827 & $\begin{array}{lll}15.60919 & 0.00000000\end{array}$ \\
\hline
\end{tabular}

From the estimation results, the ARCH and GARCH coefficient coefficients in the variance equation are significantly different from 0 . For a single yield sequence, its fluctuations are correlated, and the fluctuations of the previous period often affect the fluctuations of the next period, with significant asymmetric characteristics of the fluctuations of the investors' sentiment variables and the CSI 300 index.

At the initially, we can find that the volume of transactions last month (TURN) has the ARCH effect on the CSI 300 index, but does not have a GARCH effect and does not have a volatility spillover effect. New investor account openings last month (NIA) for the CSI 300 index with a P-value higher than 0.05, there is no volatility spillover effect. Consumer Confidence Index 
(CCI) has a significantly less P value of less than 0.05 for the CSI 300 Index, so CCI has a light spillover effect on the CSI 300 Index. Finally, the Investor Confidence Index (CICSI) has a GARCH effect on the CSI 300 Index, but it does not have the ARCH effect, so it does not have a volatility spillover effect.

Moreover, the CSI 300 index has the ARCH effect on the volume of transactions last month (TURN), but it does not have a GARCH effect and does not have the volatility spillover effect. The CSI 300 index has the ARCH effect on New investor account openings last month (NIA) added last month but does not have the GARCH effect, so it does not have a volatility spillover effect. Besides, the CSI 300 index has a GARCH effect on Consumer Confidence Index (CCI), but it does not have an ARCH effect, so it does not have a volatility spillover effect. The CSI 300 index has the ARCH effect on the Investor Confidence Index (CICSI), but it does not have a GARCH effect, so it does not have a volatility spillover effect.

In conclusion, CCI has a strong volatility spillover effect on the fluctuation of the CSI 300 index's monthly positive yield. In contrast, the other investor sentiment variables do not have a volatility spillover effect on the CSI 300 index monthly reciprocal yield. Besides, the CSI 300 index has no volatility spillover effect on all investor sentiment variables. This reflects that Chinese stock market is not stable and efficient. According to the robust and efficient market hypothesis of financial markets, any symmetrical information relating to financial markets will be fully absorbed by all financial markets at the same time in the fastest time and immediately reflected in price levels.

\section{Conclusion}

This paper aims to describe the ability of volatility models, especially the BEKK/DCC-GARCH, to capture the linkage among Chinese stock market yield fluctuations and investor sentiment and volatility spillover effects. To sum up, we have found the CCI as a single indicator that seems to be a better description of the connection among investor sentiment and volatility in Chinese stock market yields. Meanwhile, we find that no investor sentiment indicator has a two-way spillover effect with the volatility of Chinese stock market yield, which is connected to the fact that the Chinese stock market is not reliable and active.

\section{References}

Andrikogiannopoulou, A., \& Papakonstantinou, F. (2018). History-Dependent Risk Preferences: Evidence from Individual Choices and Implications for the Disposition Effect. 6th Miami Behavioral Finance Conference, I5-I I.

Bollerslev, T. (I986). Generalized autoregressive conditional heteroskedasticity. Journal of econometrics, 3I(3), 307-327.

Barberis, N., Shleifer, A., \& Vishny, R. (I998). A model of investor sentiment. Journal of financial economics, 49(3), $307-343$.

Brown, G. W. (1999). Volatility, sentiment, and noise traders. Financial Analysts Journal, 55(2), 82-90.

Brown, G. W., \& Cliff, M. T. (2004). Investor sentiment and the near-term stock market. Journal of empirical finance, II(I), I27.

Black, F. (1986). Noise. The journal of finance, 4I(3), 528-543.

Baker, M., \& Wurgler, J. (2004). A catering theory of dividends. The Journal of finance, 59(3), I I25-I I65.

Baker, M., \& Stein, J. C. (2004). Market liquidity as a sentiment indicator. Journal of Financial Markets, 7(3), 27 I-299.

Baker, M., \& Wurgler, J. (2006). Investor sentiment and the cross-section of stock returns. The journal of Finance, 6I(4), I6451680 .

Baker, M., Wurgler, J., \& Yuan, Y. (20I2). Global, local, and contagious investor sentiment. Journal of financial economics, IO4(2), 272-287.

Ben-Rephael, A., Kandel, S., \& Wohl, A. (2012). Measuring investor sentiment with mutual fund flows. Journal of financial Economics, IO4(2), 363-382.

Campbell, R., Huisman, R., \& Koedijk, K. (200I). Optimal portfolio selection in a Value-at-Risk framework. Journal of Banking \& Finance, 25(9), I789-I804.

Chen, H., Chong, T. T. L., \& Duan, X. (2010). A principal-component approach to measuring investor sentiment. Quantitative Finance, IO(4), 339-347.

De Long, J. B., Shleifer, A., Summers, L. H., \& Waldmann, R. J. (1990). Noise trader risk in financial markets. Journal of political Economy, 98(4), 703-738.

Da, Z., Engelberg, J., \& Gao, P. (2015). The sum of all FEARS investor sentiment and asset prices. The Review of Financial Studies, $28(\mathrm{I}), \mathrm{I}-32$.

Engle, R., \& Kroner, K. F. (I995). Multivariate Simultaneous Generalized ARCH. Econometric Theory, II(I), I22-I50.

Engle, R. (2002). Dynamic conditional correlation: A simple class of multivariate generalized autoregressive conditional heteroskedasticity models. Journal of Business \& Economic Statistics, 20(3), 339-350.

Fisher, K. L., \& Statman, M. (2000). Investor sentiment and stock returns. Financial Analysts Journal, 56(2), I6-23.

Hirshleifer, D., \& Shumway, T. (2003). Good day sunshine: Stock returns and the weather. The Journal of Finance, 58(3), I0091032. 
Kyle, A. S. (1985). Continuous auctions and insider trading. Econometrica: Journal of the Econometric Society, 53(6), I3I5I335.

Kaustia, M., \& Knüpfer, S. (2008). Do investors overweight personal experience? Evidence from IPO subscriptions. The Journal of Finance, 63(6), 2679-2702.

Lee, C. M., Shleifer, A., \& Thaler, R. H. (I99I). Investor sentiment and the closed-end fund puzzle. The journal of finance, 46(I), 75-109.

Lee, Y.H. (20I4). What jump effects are implicit in Nikkei 225 returns and the changes in the volatility index Japan? Investment Analysts Journal, 43(80), 7I-78.

Ni, Z. X., Wang, D. Z., \& Xue, W. J. (20I5). Investor sentiment and its nonlinear effect on stock returns-New evidence from the Chinese stock market based on panel quantile regression model. Economic Modelling, 50, 266-274.

Owji, A., \& Kontonikas, A. (2018). Modelling \& Forecasting Stock Market Volatility, Comparing Time Series Dynamics and Economic Fundamentals: A Study on the European Stock Markets.

Peng, L., \& Xiong, W. (2006). Investor attention, overconfidence and category learning. Journal of Financial Economics, 80(3), $563-602$.

Polk, C., \& Sapienza, P. (2009). The stock market and corporate investment: A test of catering theory. The Review of Financial Studies, 22(I), I87-217.

Shefrin, H., \& Statman, M. (1994). Behavioral Capital Asset Pricing Theory. Journal of Financial and Quantitative Analysis, 29(3), 323-349.

Schmeling, M. (2009). Investor sentiment and stock returns: Some international evidence. Journal of empirical finance, I6(3), 394-408.

Sayim, M., \& Rahman, H. (2015). The relationship between individual investor sentiment, stock return and volatility. International Journal of Emerging Markets, IO(3), 504-520.

Trejos, C., van Deemen, A., Rodríguez, Y. E., \& Gomez, J. M. (2019). Overconfidence and disposition effect in the stock market: A micro world-based setting. Journal of Behavioral and Experimental Finance, 21, 6I-69.

Veldkamp, L. L. (2006). Media frenzies in markets for financial information. American Economic Review, 96(3), 577-601.

Yao, J., Ma, C., \& He, W. P. (20I4). Investor herding behaviour of Chinese stock market. International Review of Economics $\&$ Finance, 29, 12-29.

Zweig, M. E. (1973). An investor expectations stock price predictive model using closed-end fund premiums. The Journal of Finance, 28(I), 67-78.

\section{Copyrights}

Copyright for this article is retained by the author(s), with first publication rights granted to the journal. This is an open-access article distributed under the terms and conditions of the Creative Commons Attribution license (http://creativecommons.org/licenses/by/4.0/). 